\title{
Experimental Investigation of Thermo-Physical Properties of Tri-Hybrid Nanoparticles in Water-Ethylene Glycol Mixture
}

\author{
Anwar IImar RAMADHAN ${ }^{1,2}$, Wan Hamzah AZMI ${ }^{1, *}$ and Rizalman MAMAT ${ }^{1}$ \\ ${ }^{I}$ Department of Mechanical Engineering, College of Engineering, Universiti Malaysia Pahang, Malaysia \\ ${ }^{2}$ Department of Mechanical Engineering, Faculty of Engineering, Universitas Muhammadiyah Jakarta, \\ Indonesia
}

('Corresponding author's e-mail: wanazmi2010@gmail.com)

Received: 5 January 2020, Revised: 6 May 2020, Accepted: 7 June 2020

\begin{abstract}
In recent years, research has focused on enhancing the thermo-physical properties of a single component nanofluid. Therefore, hybrid or composite nanofluids have been developed to improve heat transfer performance. The thermo-physical properties of the $\mathrm{Al}_{2} \mathrm{O}_{3}-\mathrm{TiO}_{2}-\mathrm{SiO}_{2}$ nanoparticles suspended in a base of water (W) and ethylene glycol (EG) at constant volume ratio of 60:40 and different volume concentrations were investigated. The experiment was conducted for the volume concentrations of 0.05 , $0.1,0.2$, and $0.3 \%$ of $\mathrm{Al}_{2} \mathrm{O}_{3}-\mathrm{TiO}_{2}-\mathrm{SiO}_{2}$ nanofluids at different temperatures of $30,40,50,60$, and $70{ }^{\circ} \mathrm{C}$. Thermal conductivity and dynamic viscosity measurements were carried out at temperatures ranging from 30 to $70{ }^{\circ} \mathrm{C}$ by using KD2 Pro Thermal Properties Analyzer and Brookfield LVDV III Ultra Rheometer, respectively. The highest thermal conductivity for tri-hybrid nanofluids was obtained at $0.3 \%$ volume concentration, and the maximum enhancement was increased up to $9 \%$ higher than the base fluid (EG/W). Tri-hybrid nanofluids with a volume concentration of $0.05 \%$ gave the lowest effective thermal conductivity of $4.8 \%$ at $70{ }^{\circ} \mathrm{C}$ temperature. Meanwhile, the dynamic viscosity of the tri-hybrid nanofluids was influenced by volume concentration and temperature. Furthermore, tri-hybrid nanofluids behaved as a Newtonian fluid for volume concentrations from 0.05 to $3.0 \%$. The properties enhancement ratio (PER) estimated that the tri-hybrid nanofluids will aid in heat transfer for all samples in the present. The new correlations for thermal conductivity and dynamic viscosity of tri-hybrid nanofluids were developed with minimum deviation. As a conclusion, the combination of the enhancement in thermal conductivity and dynamic viscosity for tri-hybrid at $0.3 \%$ volume concentration was found the optimum condition with more advantage for heat transfer than other concentrations.
\end{abstract}

Keywords: Ethylene glycol-water, Dynamic viscosity, Thermal conductivity, Tri-hybrid nanofluids

\section{Introduction}

Nanofluid is a suspension of liquid containing metal or non-metallic nanoparticles of typical size (1 - $100 \mathrm{~nm}$ ) dispersed into the base liquid. In 1995, the concept of nanofluids was first introduced by Choi et al. [1]. This new method was proven to increase heat transfer by improving the thermo-physical properties of the nanofluids. Nanofluids are known for their application in the heating and cooling process. The main cooling process is an important part of industrial applications such as power plants, chemical processes, microelectronics, transportation, and automotive cooling systems [2,3]. The existence of solid particles leads to interesting characteristics in the fundamental thermo-physical properties of nanofluids. Thermal conductivity, viscosity, density, and stability have been investigated in recent years by many researchers $[4,5]$.

The method of nanofluid preparation is important to minimize the agglomeration of the nanoparticles, and hence improve the stability. The most common processes used in nanofluid preparation 
http://wjst.wu.ac.th

are 1-step and 2-step methods. The 1-step method is the process of synthesizing nanoparticles and simultaneously dispersing them in a base liquid. However, this method is not practical for industry, which only applies to low vapor pressure liquids. Another method of nanofluid preparation is known as the 2step method. There are 2 processes in this method, namely (i) the synthesis of nanoparticles in powder form and (ii) spreading the nanoparticles into the base liquid to form a stable and homogeneous solution [6,7]. Most nanofluids that use oxide particles and carbon nanotubes are produced through a two-step method [8-10]. The 2-step method is preferable for the production of nanofluids on a large scale and is thus applicable for industry. However, the challenge of using the 2-step method is that agglomeration and nanoparticles tend to settle quickly [11]. The 2-step method is the most dominant method compared to the 1-step method for nanofluid preparation.

Several recent studies have discussed the topic of hybrid or composite nanofluids [12,13]. Hybrid or composite nanofluids are considered an extension of research work for single nanofluids, which can be carried out through a combination of 2 or more different nanoparticles- either in mixed or dispersed composites in liquids [14]. Composite or hybrid materials are elements that combine chemical and physical properties. The aim of synthesizing hybrids or nanofluid composites is to improve the properties of single nanoparticles, in which a better increase in thermal properties or rheological properties can be achieved. Hybrid nanofluid is expected to achieve good thermal performance when compared to a single nanofluid [15]. Recently, some papers regarding nanofluid hybrids have been reviewed by Hamzah et al. [16] and Sidik et al. [17]. Both papers were presented on hybrid nanofluid preparation, performance, and application methods. Therefore, investigations on thermal conductivity and viscosity are important in understanding hybrid nanofluid behavior for further implementation in heat transfer applications. Thermal conductivity is an important factor affecting the increase in heat transfer $[18,44]$. There are several factors that influence thermal conductivity, such as: concentration, temperature, particle size, surface ratio to nanoparticle volume, and nanofluid stability [19-22]. Turgut et al. [23], proved that thermal conductivity increased by $7.4 \%$ with a volume fraction of particles above alkaline liquids. Investigation of $\mathrm{Al}_{2} \mathrm{O}_{3}-\mathrm{Cu}$ composite nanofluid with water as a basic liquid was carried out by Suresh et al. [24]; they reported an increase of up to $12 \%$ with increasing volume concentration. In another paper, Hamid et al. [25], the thermo-physical properties of $\mathrm{TiO}_{2}-\mathrm{SiO}_{2}$ nanoparticles suspended in a base fluid of water (W) and ethylene glycol (EG) mixture with 60:40 volume ratio were investigated. They found the highest thermal conductivity for $\mathrm{TiO}_{2}-\mathrm{SiO}_{2}$ nanofluids was obtained with a ratio of 20:80, and the maximum enhancement exceeded up to $16 \%$ higher than the base fluids.

Ho et al. [26], determined the nanofluid dynamic viscosity of $\mathrm{Al}_{2} \mathrm{O}_{3}$-MEPCM composites. They observed an increase in the mass fraction of the nanoparticles. In another study, Esfe et al. [12] used $\mathrm{Ag}-\mathrm{MgO} /$ water composite nanofluid. They found that the dynamic viscosity of the composite nanofluid increased with an increase in volume fraction and build correlation for viscosity. In comparison, their correlation predicted a higher value than the existing correlation in the literature. Soltani et al. [27] conducted a viscosity experiment with MgO-MWCNT composite nanofluid within the range of $0.1-1.0 \%$ concentration and temperature range of $30-60{ }^{\circ} \mathrm{C}$. The observed temperature effect is important for nanofluids at high concentrations. Their findings showed that nanofluid acts as a Newtonian fluid.

The thermo-physical properties of various types of hybrid nanofluids are very important to study. It aims to understand the behaviors and factors that affect the properties that can improve heat transfer performance. Based on the information obtained by the authors, the study of the effect of mixed ratios for the 3 nanoparticles in the shape of hybrid nanofluids is limited in the literature. Furthermore, the use of hybrid nanofluids with 2 different nanoparticles will result in increased viscosity relative to single nanofluid components [28]. Based on this problem, this study was conducted by emphasizing the influence of the ratio of three nanoparticles on thermal-physical properties. The thermal conductivity and dynamic viscosity of $\mathrm{Al}_{2} \mathrm{O}_{3}-\mathrm{TiO}_{2}-\mathrm{SiO}_{2}$ nanofluids or tri-hybrid nanofluids for heat transfer applications was investigated. 


\section{Materials and methods}

\section{Preparation of tri-hybrid nanofluids}

The preparation of tri-hybrid nanofluids involved 3 different types of single nanofluids, namely, $\mathrm{Al}_{2} \mathrm{O}_{3}, \mathrm{TiO}_{2}$, and $\mathrm{SiO}_{2}$ mixed together and dispersed in the base fluid of water/EG mixture. All the single nanofluids were procured from US Research Nanomaterials, Inc. The respective nanoparticle sizes for $\mathrm{Al}_{2} \mathrm{O}_{3}, \mathrm{TiO}_{2}$, and $\mathrm{SiO}_{2}$ were 13, 50, and $30 \mathrm{~nm}$, with purity of 99.8, 99, and $99.99 \%$, respectively. The properties of each nanoparticle are given in Table 1. The base fluid used in the present study was a mixture of water and EG at a ratio of $60: 40(\mathrm{vol} \%)$. The properties of ethylene glycol are presented in Table 2. The nanoparticle size characterization of the tri-hybrid nanofluids was performed using the field scanning electron microscope (FESEM) technique for $\mathrm{Al}_{2} \mathrm{O}_{3}, \mathrm{TiO}_{2}$, and $\mathrm{SiO}_{2}$ nanoparticles. The FESEM images for nanoparticles are shown in Figure 1.

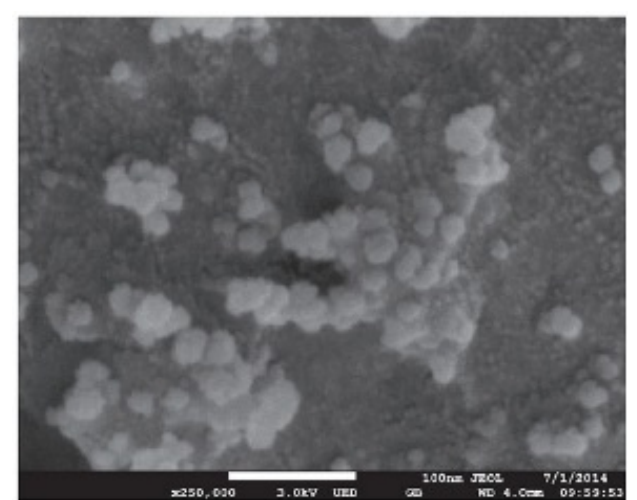

(a) $\mathrm{Al}_{2} \mathrm{O}_{3}$

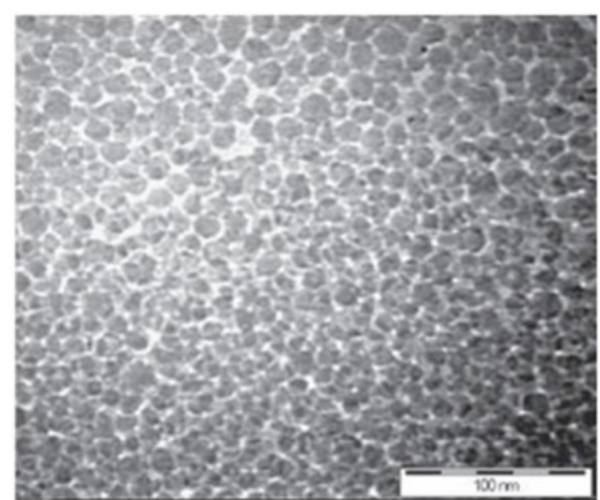

(b) $\mathrm{SiO}_{2}$

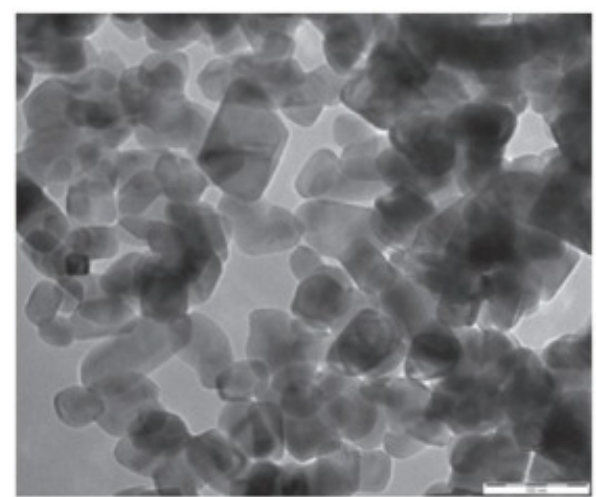

(c) $\mathrm{TiO}_{2}$

Figure 1 Field Scanning Electron Microscope (FESEM) images for $\mathrm{Al}_{2} \mathrm{O}_{3}, \mathrm{TiO}_{2}$, and $\mathrm{SiO}_{2}$ nanoparticles [9]. 
Table 1 Properties of $\mathrm{Al}_{2} \mathrm{O}_{3}, \mathrm{TiO}_{2}$, and $\mathrm{SiO}_{2}$ nanoparticles [9].

\begin{tabular}{llll}
\hline Properties & $\mathbf{A l}_{2} \mathbf{O}_{3}$ & $\mathbf{T i O}_{2}$ & $\mathbf{S i O}_{\mathbf{2}}$ \\
\hline Molecular mass, $\mathrm{g} \mathrm{mol}^{-1}$ & 101.96 & 79.86 & 60.08 \\
\hline Average particle diameter, $\mathrm{nm}$ & 13 & 50 & 30 \\
\hline Density, $\mathrm{kg} \mathrm{m}^{-3}$ & 4,000 & 4,230 & 2,220 \\
\hline Thermal conductivity, $\mathrm{W} \mathrm{m}^{-1} \mathrm{~K}^{-1}$ & 40 & 8.4 & 1.4 \\
\hline Specific heat, $\mathrm{J} \mathrm{kg}^{-1} \mathrm{~K}^{-1}$ & 773 & 692 & 745 \\
\hline
\end{tabular}

Table 2 Properties of ethylene glycol (EG) [9].

\begin{tabular}{lc}
\hline \multicolumn{1}{c}{ Properties } & Ethylene Glycol (EG) \\
\hline Vapour pressure, $\mathrm{mmHg}$ at $20^{\circ} \mathrm{C}$ & 0.08 \\
\hline Boiling point, ${ }^{\circ} \mathrm{C}$ & $195-198$ \\
\hline Melting point, ${ }^{\circ} \mathrm{C}$ & -13 \\
\hline Density, $\mathrm{g} \mathrm{ml}{ }^{-1}$ at $25{ }^{\circ} \mathrm{C}$ & 1.113 \\
\hline
\end{tabular}

The 2-step method was used for the preparation of tri-hybrid nanofluids. Tri-hybrid nanofluids are prepared by mixing the 3 nanofluids $\left(\mathrm{Al}_{2} \mathrm{O}_{3}, \mathrm{TiO}_{2}\right.$ and $\left.\mathrm{SiO}_{2}\right)$ together, undergoing mixing- and sonicationbased processes as per Ramadhan et al. [43]. The preparation of the nanofluid initially begins with the calculation of the required volume according to the concentration performed for the experiments. Further, in this study, the tri-hybrid nanofluids were prepared at volume concentrations of $0.05,0.1,0.2$, and 0.3 $\%$. The nanofluids were first prepared at the highest concentration, $0.3 \%$, and then diluted to lower concentrations.

The single nanofluids $\mathrm{Al}_{2} \mathrm{O}_{3}, \mathrm{TiO}_{2}$, and $\mathrm{SiO}_{2}$ were supplied in a water suspension with weight concentrations of 20,40, and $25 \%$ for $\mathrm{Al}_{2} \mathrm{O}_{3}, \mathrm{TiO}_{2}$, and $\mathrm{SiO}_{2}$, respectively. Eq. (1) [29] is used to convert from weight concentration to volume concentration. The dilution from higher volume concentration to lower volume concentration utilized Eq. (2) $[30,46,47,48]$ by adding the base fluid $(\Delta \mathrm{V})$.

$$
\begin{aligned}
& \phi=\frac{\omega \rho_{w}}{\frac{\omega}{100} \rho_{w}+\left(1-\frac{\omega}{100}\right) \rho_{p}} \\
& \Delta V=\left(V_{2}-V_{1}\right)=V_{1}\left(\frac{\phi_{1}}{\phi_{2}}-1\right)
\end{aligned}
$$

All single nanofluids were mixed together at a volume ratio of $1 / 3: 1 / 3: 1 / 3$ to form a tri-hybrid nanofluid. Total volumes of $100 \mathrm{~mL}$ were prepared for each concentration of the tri-hybrid nanofluids. The combined solution from the three single $\mathrm{Al}_{2} \mathrm{O}_{3}, \mathrm{TiO}_{2}$, and $\mathrm{SiO}_{2}$ nanofluids were mixed together using a magnetic stirrer for $120 \mathrm{~min}$. Then, the solution underwent a sonication process using an ultrasonic bath to enhance stability.

\section{Stability of tri-hybrid nanofluids}

The investigation on the stability of the tri-hybrid nanofluids in the present study was conducted through visual observation, via measurement by UV-Vis Spectrophotometer. The sedimentation through visual observation was conducted up to 14 days. Nanofluids were considered stable when the 
concentration was constant. Previously, the same method to observe visual sedimentation of prepared nanofluids was used Azmi et al. [31]. The UV-Vis spectrophotometry measurement was conducted for 10 days $(250 \mathrm{~h})$ by varying the sonication time. The wavelength of the UV-Vis spectrophotometer was set at $900 \mathrm{~nm}$, following the study by Hamid et al. [32]. The UV-Vis spectrophotometer measures the absorption and light intensity of the scattering light after passing the nanofluid by comparing the intensity level to what it was when it passed the base fluid. The absorbance ratio of sonication times is different during sedimentation time at a constant wavelength $(\lambda)$ of $900 \mathrm{~nm}$. The stability evaluation by UV-Vis spectrophotometer was also used by previous studies $[29,49]$.

\section{Thermal conductivity measurement of tri-hybrid nanofluids}

The method of thermal conductivity measurement followed the ASTM D5334 and IEEE 442-1981 standards, using KD2 Pro Property Analyzer (Decagon Devices), is shown in Figure 2. Part of the thermal test sample conductivity consists of a KS-1 sensor to read of $k$ [W/m K], a measuring bottle to put samples to be tested, and a KD2 Pro controller, which is an important part of thermal conductivity measuring device. The KD2 Pro instrument uses a transient line heat source to measure thermal properties. Thermal conductivity measurements are performed for temperatures varying from 30 to $70{ }^{\circ} \mathrm{C}$. A water bath was used to maintain a constant sample temperature during the experiment. Previous to the sample measurement, the validation of thermal conductivity values from thermal conductivity sensors was evaluated using standardized liquid glycerine supplied by Decagon Devices. The measured $k$ was $0.286 \mathrm{~W} / \mathrm{m} \mathrm{K}$ with an accuracy $\pm 0.35 \%$. Thermal conductivity measurements were performed several times for each sample and temperature, and an average value was taken; the measurement time for each set data was about $15 \mathrm{~min}$ for each set data at different temperatures. It is important to minimize the occurrence of errors in measurements with free convection due to temperature variation along the sensor that directly touches the liquid sample.

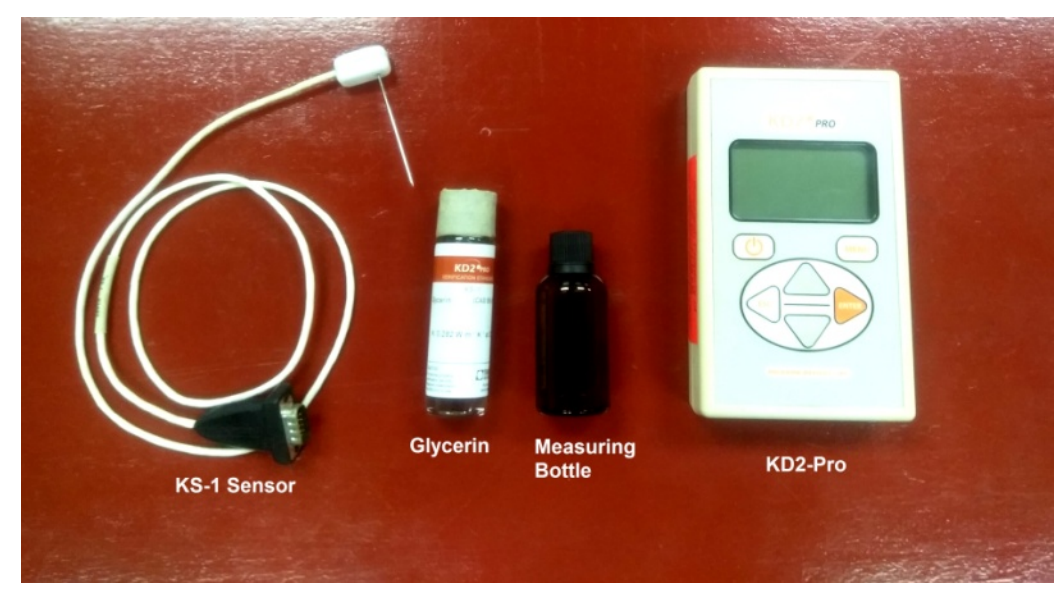

Figure 2 KD2 Pro thermal property measurement apparatus for thermal conductivity measurement.

\section{Dynamic viscosity measurement of tri-hybrid nanofluids}

Viscosity measurement was done using a Brookfield LVDV III Ultra Rheometer with a water bath circulation. Operating conditions of Rheometer for viscosity measurement range from 1 to $6 \times 10^{6} \mathrm{mPa}$.s. The sample of $16 \mathrm{~mL}$ was added to the cylinder jacket and pasted into the Rheometer. The RheoCal program was used for measuring the viscosity connected to the controller. Sample viscosity was evaluated by varying the velocity of the spindle. Dynamic viscosity measurements were performed with a temperature variation of $30 \sim 70{ }^{\circ} \mathrm{C}$. The circulating water bath was used to control the sample 
temperature. The measurements were repeated 5 times and the average value was reported. Dynamic viscosity measurement apparatus is shown in Figure 3. Basic liquid 60:40 (water: EG) at different temperatures were validated by the data contained in the literature. The dynamic viscosity measurements were performed for $\mathrm{Al}_{2} \mathrm{O}_{3}-\mathrm{TiO}_{2}-\mathrm{SiO}_{2}$ or tri-hybrid nanofluids.

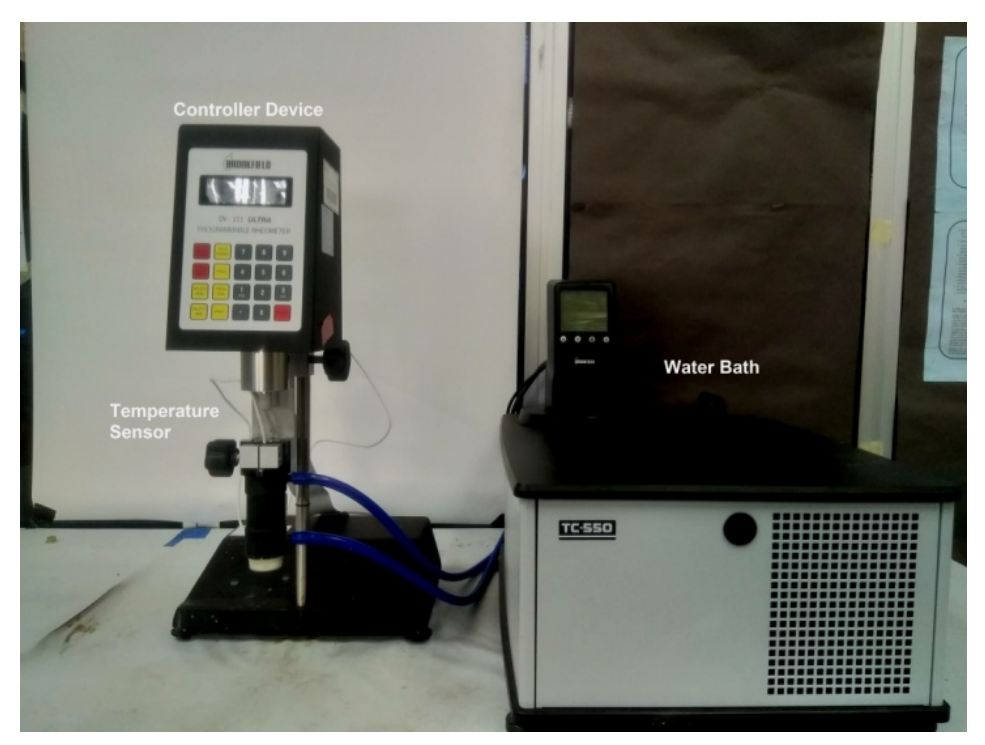

Figure 3 Brookfield LVDV III Ultra Rheometer for the measurement of dynamic viscosity (from left: temperature sensor, controller device and water bath).

\section{Results and discussion}

\section{Stability of tri-hybrid nanofluids}

The stability of the $\mathrm{Al}_{2} \mathrm{O}_{3}-\mathrm{TiO}_{2}-\mathrm{SiO}_{2}$ nanofluids was further confirmed by the concentration ratio, $\phi_{r}$ presented in Figure 4. The concentration ratio of $0.1 \%$ vol concentration of the tri-hybrid nanofluids was used for 6 different sonication hours. The ideal absorbance ratio of one $(100 \%)$ presented the ideal stability of the fluid. The concentration ratio of mixture sonication at $0.5,1$, and $2 \mathrm{~h}$ started to decrease after being stored for $24 \mathrm{~h}$ and kept decreasing until 10 days $(240 \mathrm{~h})$. With sonication time of 5 and $10 \mathrm{~h}$, it remained at good concentration ratio value at about $(70 \sim 80 \%)$ until 10 days. From this figure, it can be seen that the $10 \mathrm{~h}$ sonication time shows the best absorbance ratio compared to others. Thus, the preparation of the tri-hybrid nanofluids in the present study used $10 \mathrm{~h}$ for the sonication process. The findings of concentration ratio obtained $80 \%$ from 150 to $240 \mathrm{~min}$. This condition was stable. Figure 5 shows images of tri-hybrid nanofluids $\left(\mathrm{Al}_{2} \mathrm{O}_{3}-\mathrm{TiO}_{2}-\mathrm{SiO}_{2}\right)-\mathrm{W} / \mathrm{EG}$ at volume concentrations of 0.05 . 0.1, 0.2 , and $0.3 \%$. Tri-hybrid nanofluids $\left(\mathrm{Al}_{2} \mathrm{O}_{3}-\mathrm{TiO}_{2}-\mathrm{SiO}_{2}\right)-\mathrm{W} / \mathrm{EG}$ images were taken only after preparation and after 14 days. From Figure 5(a), no sedimentation of particles was observed after the nanofluids were prepared. The sedimentation of particles started to be noticeable at 7 days. After 14 days, the sedimentation could be clearly seen, as shown in Figure 5(d). The sedimentation from this observation was affected by the gravity falling motion of the particles in the tube. 


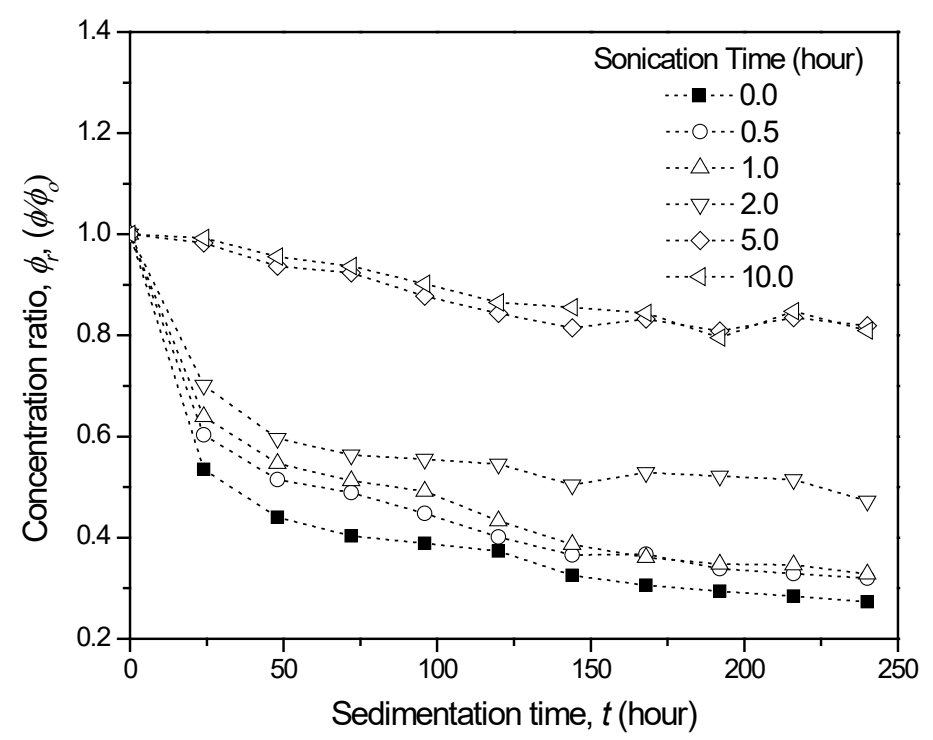

Figure 4 The concentration ratio of tri-hybrid nanofluids for different sonication times within 10 days.

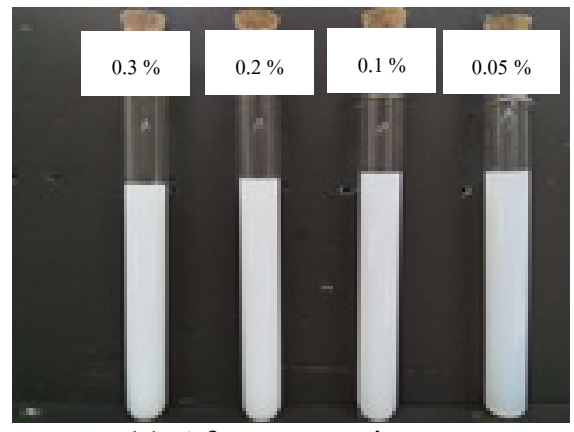

(a) After preparation

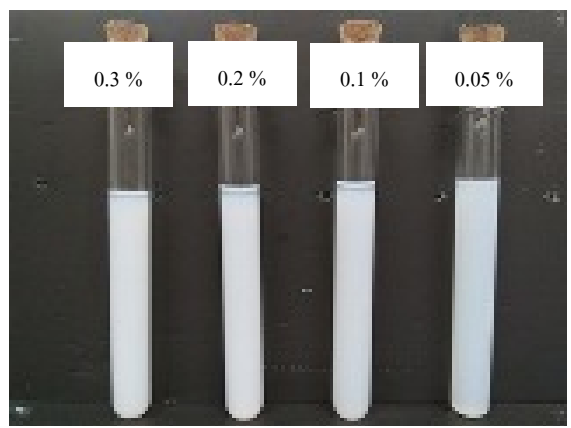

(c) 7 days

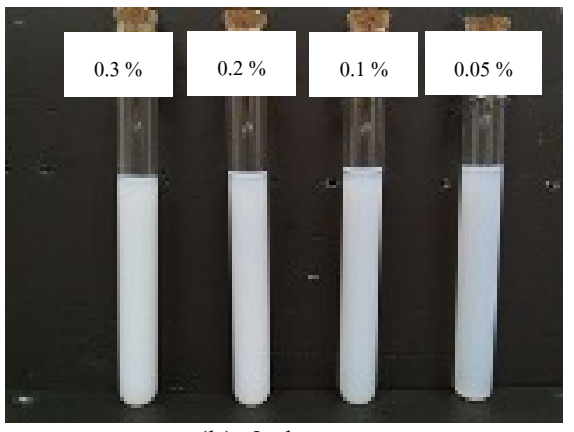

(b) 3 days

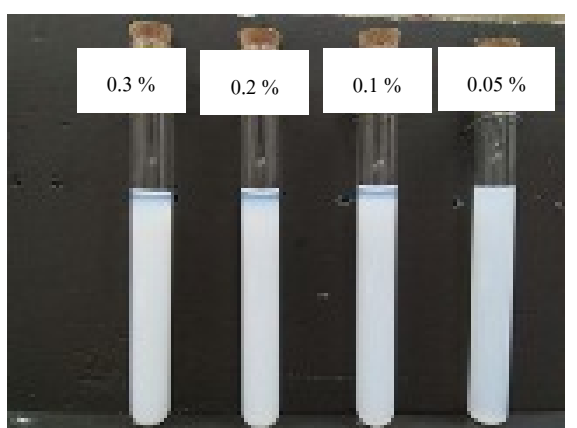

(d) 30 days

Figure 5 Sedimentation observation of tri-hybrid nanofluids: (a) after preparation, (b) 3 days, (c) 7 days, and (d) 30 days. 


\section{Validation of thermal conductivity and dynamic viscosity}

Thermal conductivity data and viscosity need to be validated by comparing with ASHRAE [33] for EG/Water $(60: 40)$ medium. For the measurement of thermal conductivity using KD2 Pro, data validation resulted with $1.5 \%$ deviation, presented in Figure 6. Deviations for measurable data were less than $1.0 \%$ compared to ASHRAE [33]. Reddy et al. [34] performed validation tests for deviations from their base fluid up to $2.5 \%$ compared to ASHRAE [33]. Furthermore, the same temperature range and water/EG ratio on validation of current viscosity measurements was investigated by other papers [30,35,36]. Figure 6(b) indicates that the viscosity data is in a good pattern and in accordance with ASHRAE [33]. In addition, data for base fluid composed of water and EG mixture is very accurate with ASHRAE data trends that lower viscosity on temperature. Therefore, further measurements and investigations for thermal conductivity and dynamic viscosity of tri-hybrid nanofluids were performed.

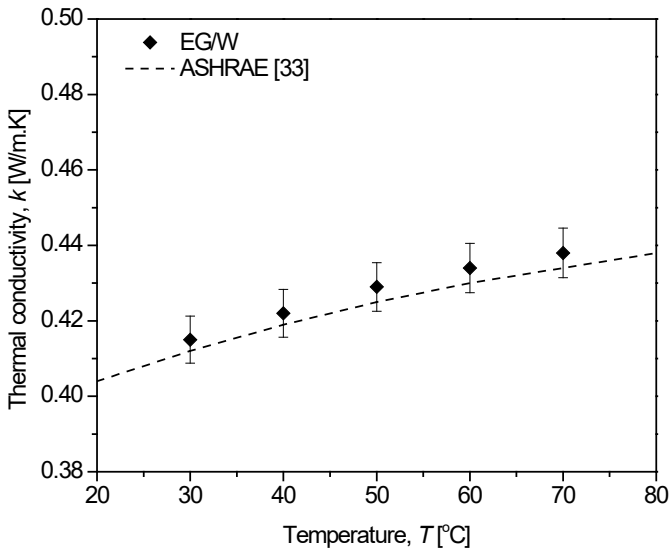

(a) Thermal conductivity

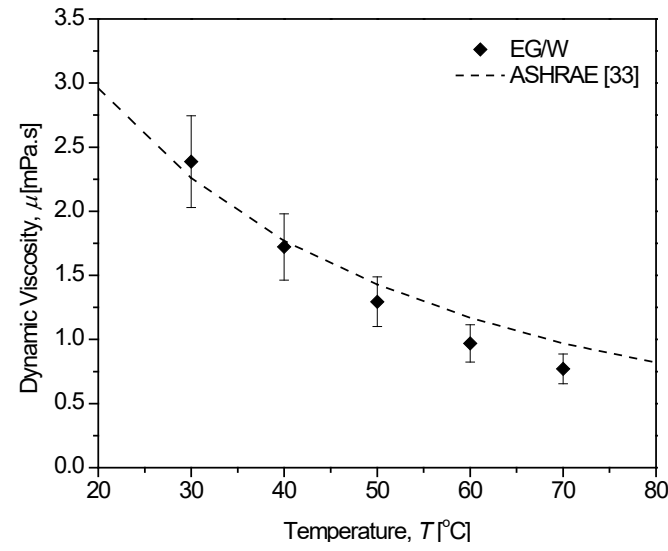

(b) Dynamic viscosity

Figure 6 Validation (a) thermal conductivity and (b) dynamic viscosity data of EG/Water (40:60) with ASHRAE.

\section{Thermal conductivity of tri-hybrid nanofluids}

The relationships between tri-hybrid nanofluids thermal conductivity and temperature at volume concentrations of $0.05 \sim 0.3 \%$ are presented in Figure 7. Thermal conductivity of the tri-hybrid nanofluids for the various volume concentrations increased as temperature increased and was higher than base fluid. Furthermore, the highest thermal conductivity was obtained for the volume concentration of $0.3 \%$. Meanwhile, the volume concentration of $0.05 \%$ provided the lowest thermal conductivity among the investigated temperatures. In this study, the relationship between the composition ratio of nanoparticles $(1 / 3: 1 / 3: 1 / 3)$ in the tri-hybrid nanofluids to increased thermal conductivity was influenced by 3 nanoparticles that have different sizes. The diameters of $\mathrm{Al}_{2} \mathrm{O}_{3}$ and $\mathrm{SiO}_{2}$ nanoparticles are $13 \mathrm{~nm}$ and $22 \mathrm{~nm}$, wherein both nanoparticles are smaller than $\mathrm{TiO}_{2}$ nanoparticles that have a size of $50 \mathrm{~nm} . \mathrm{Al}_{2} \mathrm{O}_{3}$ and $\mathrm{SiO}_{2}$ nanoparticles play a role in conduction by fulfilling larger $\mathrm{TiO}_{2}$ nanoparticle spaces. To increase the contact area for conduction between molecules, resulting in a higher rate of heat transfer during a collision by the Brownian motion [37], requires a special arrangement of the three type nanoparticles. The effective thermal conductivity of tri-hybrid nanofluids are presented in Figure 8. The results revealed that the effective thermal conductivity increased with $0.3 \%$ volume concentration in the tri-hybrid nanofluids; except for $0.05 \%$ volume, where the effective thermal conductivity of nanofluids were lowest. Effective thermal conductivity in tri-hybrid nanofluids can significantly affect the relationship between volume concentration and each set of temperatures. 
http://wjst.wu.ac.th

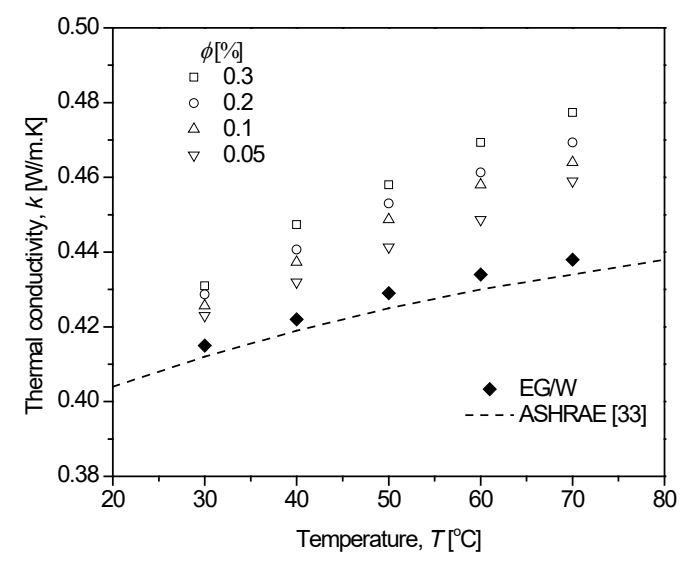

Figure 7 The experimental thermal conductivity of tri-hybrid nanofluids.

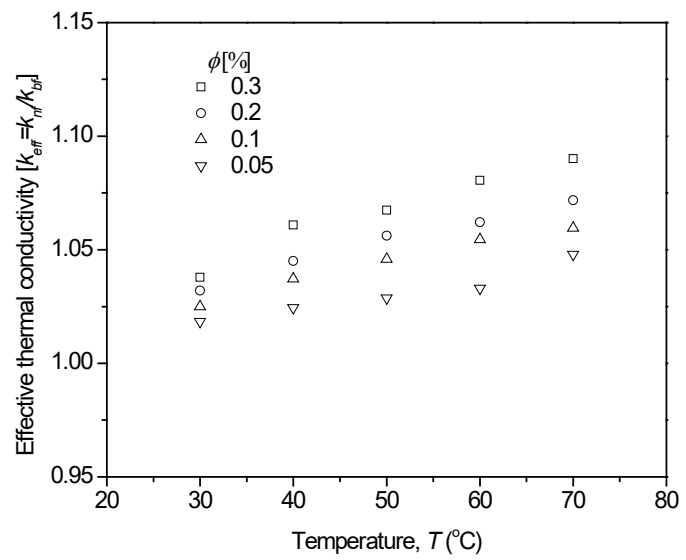

Figure 8 The effective thermal conductivity of tri-hybrid nanofluids.

\section{Dynamic viscosity of tri-hybrid nanofluids}

Figure 9 illustrates the dynamic viscosity against shear rate in the range of $920 \leq \gamma \leq 4320 \mathrm{~s}-1$ for $0.05 \%$ vol concentration of tri-hybrid nanofluids. The results indicate that the dynamic viscosity remained constant with the increase of shear rate for $0.05 \%$ vol nanofluid. The shear-independent viscosity demonstrates that the tri-hybrid nanofluids behaved as Newtonian fluids within the temperatures studied. The dynamic viscosity of the $\mathrm{Al}_{2} \mathrm{O}_{3}-\mathrm{TiO}_{2}-\mathrm{SiO}_{2}$ nanofluids for different temperatures had a significant effect on the concentration volume of $0.05 \%$. A temperature of $30{ }^{\circ} \mathrm{C}$ provides a higher dynamic viscosity than $40,50,60$, and $70{ }^{\circ} \mathrm{C}$, as shown in Figure 9. This is probably due to the different intensities of $\mathrm{Al}_{2} \mathrm{O}_{3}, \mathrm{TiO}_{2}$ and $\mathrm{SiO}_{2}$ nanoparticles in the composition ratio $(1 / 3: 1 / 3: 1 / 3)$ in tri-hybrid nanofluids. 


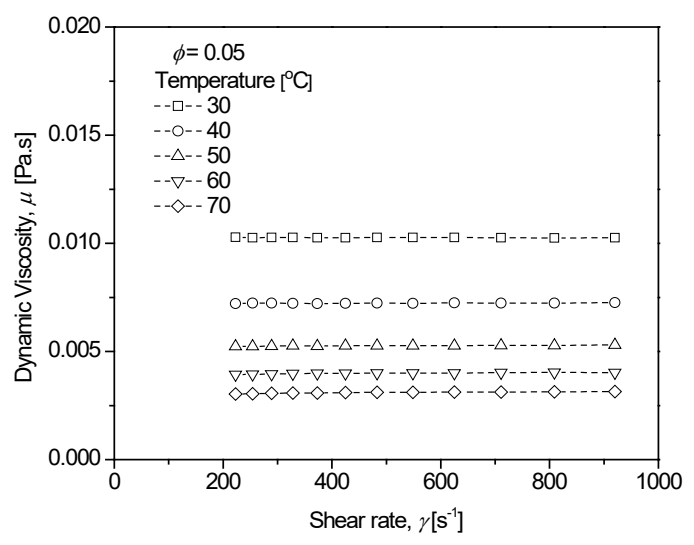

(a)

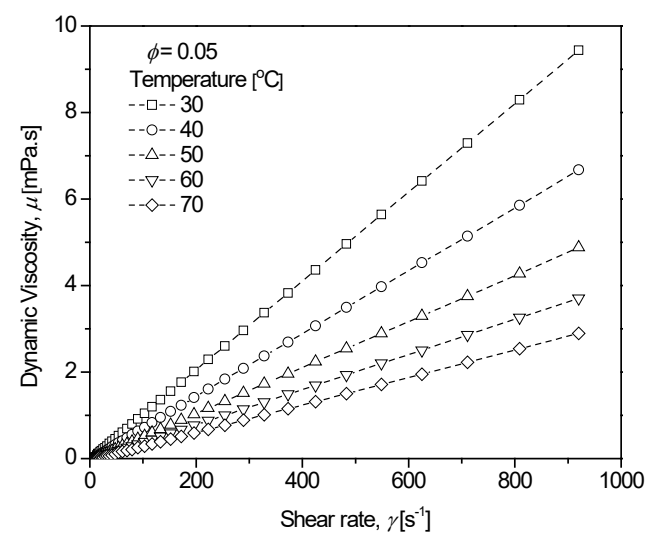

(b)

Figure 9 Variation of dynamic viscosity with shear rate.

Figure 10 shows the dynamic viscosity for various volume concentrations of tri-hybrid nanofluids in the temperature range of $30 \sim 70^{\circ} \mathrm{C}$. The viscosity for all volume concentration followed the base fluid trend, whereby it decreased exponentially with temperature. The viscosity of the volume concentration of 0.3 was higher than the values of those of $0.2,0.1$, and $0.05 \%$. The volume concentration of $0.3 \%$ showed the highest value for viscosity at all temperatures. The dynamic viscosity of the tri-hybrid nanofluids decreased slightly and varied by the differences in the composition ratio of $\mathrm{Al}_{2} \mathrm{O}_{3}, \mathrm{TiO}_{2}$, and $\mathrm{SiO}_{2}$ nanoparticles of $1 / 3: 1 / 3: 1 / 3$ in the tri-hybrid nanofluids contributing to the difference in the interactions of those particles with a base fluid. However, the effect of temperature on the $\mathrm{Al}_{2} \mathrm{O}_{3}-\mathrm{TiO}_{2}$ $\mathrm{SiO}_{2}$ nanofluid viscosity for all mixed ratios decreased with increasing temperature and was evidenced by Asadi et al. [38].

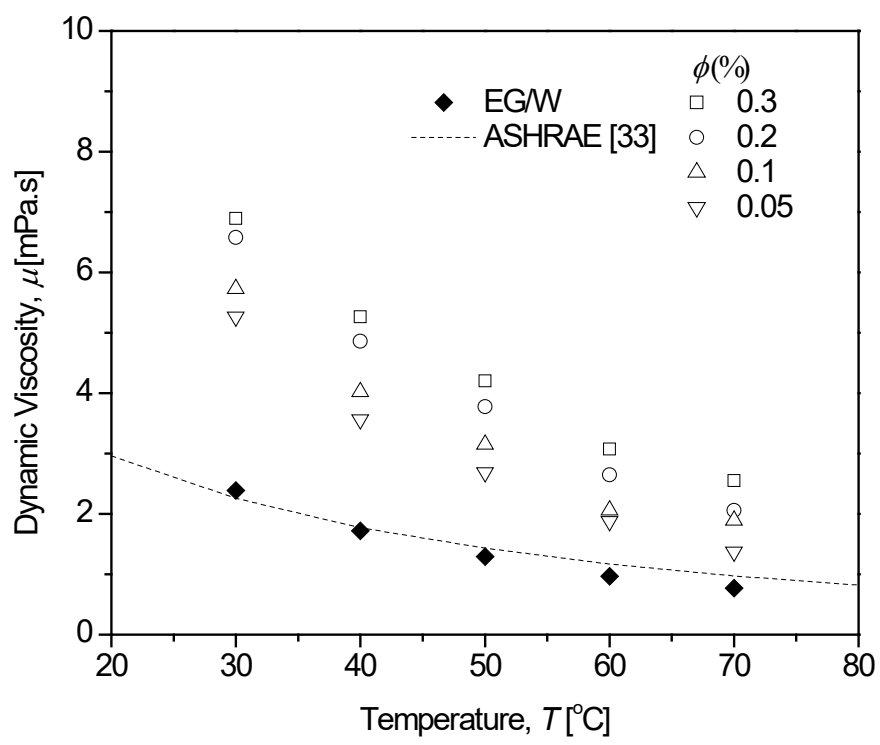

Figure 10 Variation of dynamic viscosity with temperature. 
The variation of relative viscosity with temperature is shown in Figure 11. From the figure, the maximum relative viscosity for all volume concentrations occurred at the different temperatures of $30 \sim 70{ }^{\circ} \mathrm{C}$. For the volume concentration of $0.3 \%$, the viscosity ratio was higher at $30{ }^{\circ} \mathrm{C}$, and then increased at $40 \sim 70{ }^{\circ} \mathrm{C}$. Similarly, this pattern also applied to the volume concentrations of $0.2,0.1$, and $0.05 \%$. At the volume concentration 0.2 , relative viscosity value rose and fell at $30{ }^{\circ} \mathrm{C}$ at around 2.8 , then increased from 40 to $70{ }^{\circ} \mathrm{C}$. In addition, the values increased significantly for temperatures of $60 \sim 70{ }^{\circ} \mathrm{C}$, with a maximum increase of 5.4 times compared to base fluid. It can be concluded that the relative viscosity distribution for all volume concentrations is always below $0.3 \%$ vol in the investigated temperature range. The results also showed a specific tendency for viscosity at different volume concentrations. This may be due to different effects on shear flow resistance due to the presence of 3 different types of nanoparticles with different concentration volumes and particle sizes.

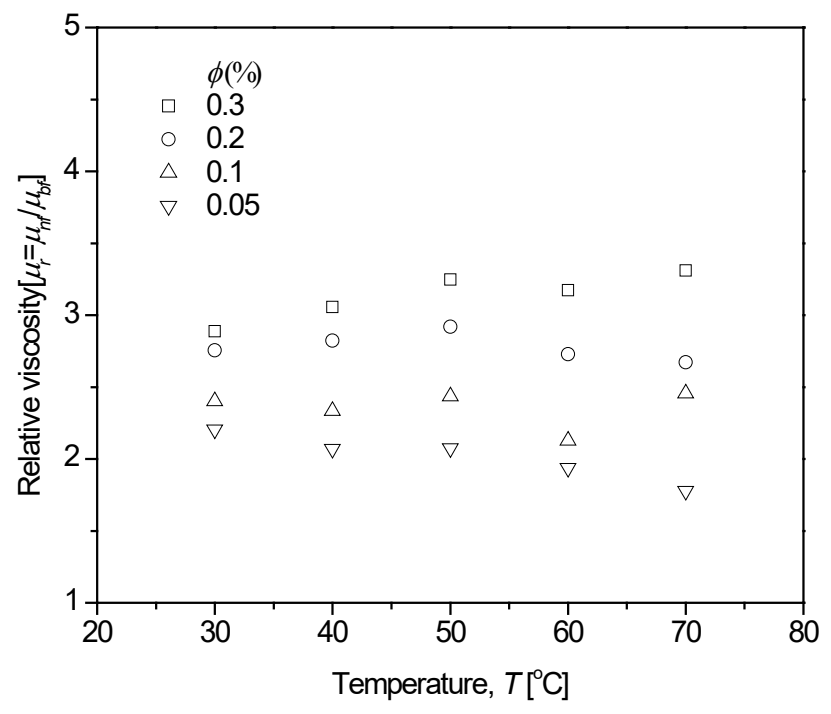

Figure 11 Variation of relative viscosity with temperature.

\section{Comparison with literature}

Figures 12(a) and (b) demonstrate comparisons of the effective thermal conductivity and relative viscosity of the present study with the data from Nabil et al. [39], Murshed et al. [40], and Azmi et al. [30]. In this study, the effective thermal conductivity of tri-hybrid nanofluids was increased by $1.02-1.06$ times compared to a base fluid for concentration $0.1 \%$. Murshed et al. [40], used $\mathrm{Al}_{2} \mathrm{O}_{3}$ nanoparticle with $0.5 \%$ vol concentration of a base fluid of EG/water mixture. They proved that the experimental values of the different thermal conductivities of nanofluid significantly increased with fluid temperature. This is due to the high fluid temperature, which increases the movement of Brownian nanoparticles and also decreases the base fluid viscosity. The influence of intense Brownian motion meant the contribution of micro connectivity to heat transport increased, resulting in increased thermal conductivity of nanofluid. A study by Nabil et al. [39] used $\mathrm{TiO}_{2}-\mathrm{SiO}_{2}$ with EG/water as a base fluid. They presented the results of the thermal conductivity of the $\mathrm{TiO}_{2}-\mathrm{SiO}_{2}$ nanofluids enhancement with increasing concentration and temperature. The relative viscosity in their research is almost identical compared to this study for temperatures between 30 and $50{ }^{\circ} \mathrm{C}$.

In another paper, Azmi et al. [30] performed relative viscosity measurements for $\mathrm{TiO}_{2}$ nanoparticles in EG/water based liquids at a concentration of $0.5 \%$. The results showed that the relative viscosity in the range studied increased about 1.05 - 1.12 times compared to the water/EG mixture. The occurrence of 
http://wjst.wu.ac.th

relative viscosity fluctuations in an unspecified temperature range. Their relative viscosity was the lowest value compared to the others, as shown in Figure 12(b). According to Sundar et al. [28], the magnitude of the increase in thermal conductivity or relative viscosity depends on the type of nanoparticle and the base fluid, thus observed and illustrated in Figures 12(a) and 12(b).

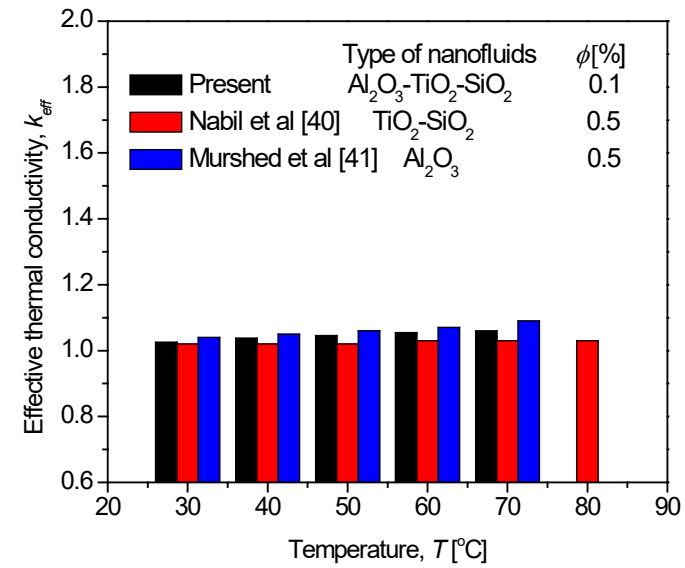

(a) thermal conductivity

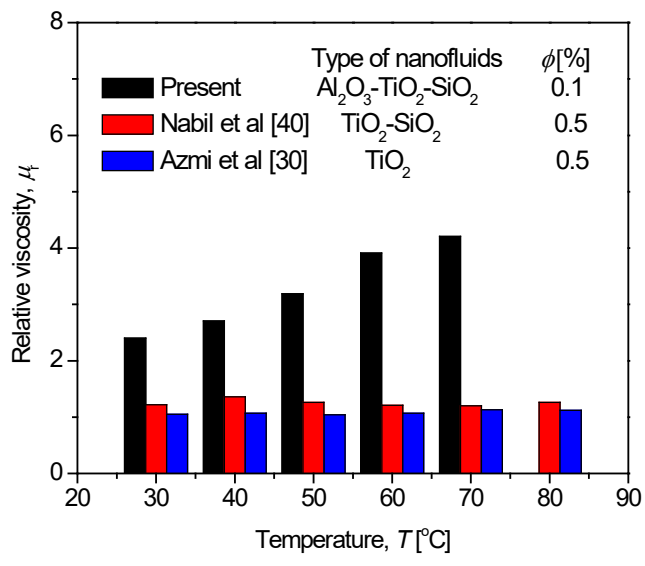

(b) dynamic viscosity

Figure 12 Comparison of tri-hybrid nanofluids properties with data from the literature.

\section{Conclusions}

In this study, thermal conductivity and dynamic viscosity of tri-hybrid nanofluids were investigated for four concentration volumes, and temperatures from 30 to $70{ }^{\circ} \mathrm{C}$. The experimental results showed that the concentration volume of $0.3 \%$ obtained the best effective thermal conductivity and relative viscosity compared to $0.05 \sim 0.2 \%$. Therefore, in this study, different concentration volumes became the control parameters and performance studied. In terms of increased thermal conductivity, $0.3 \%$ volume concentration provided a maximum increase of up to $9 \%$, while it was observed that $0.05 \%$ had the least increase for dynamic viscosity, which was approximately 2.2 times the average compared to other ratios. The optimum of the concentration volume was $0.3 \%$, where the increase in thermal conductivity and dynamic viscosity had more advantages than other concentration volumes. However, experimental investigations on heat transfer are required to determine the actual performance of this volume of concentration.

\section{Acknowledgements}

The authors are grateful to the Ministry of Higher Education Malaysia and Universiti Malaysia Pahang (www.ump.edu.my) for financial support given under FRGS/1/2018/TK10/UMP/02/10, RDU190146 and PGRS1903147. The authors also thank the research team from the Centre of Excellence for Advanced Research in Fluid Flow (CARIFF) and the Advanced Automotive Liquids Laboratory (A2LL), who provided insight and expertise that greatly assisted in the present research work. 
http://wjst.wu.ac.th

\section{References}

[1] SUS Choi and JA Eastman. Enhancing thermal conductivity of fluids with nanoparticles. In: Proceedings of the 1995 International Mechanical Engineering Congress and Exhibition, San Francisco, United States. 1995, p. 99-106.

[2] A Nuntaphan, S Vithayasai, N Vorayos, N Vorayos and T Kiatsiriroat. Use of oscillating heat pipe technique as extended surface in wire-on-tube heat exchanger for heat transfer enhancement. Int. Comm. Heat Mass Tran. 2010; 37, 287-92.

[3] R Saidur, KY Leong and HA Mohammad. A review on applications and challenges of nanofluids, Renew. Sustain. Energ. Rev. 2011; 15, 1646-68.

[4] M Chandrasekar and S Suresh. A review on the mechanisms of heat transport in nanofluids. Heat Tran. Eng. 2009; 30, 1136-50.

[5] S Lee, SUS Choi, S Li and JA Eastman. Measuring thermal conductivity of fluids containing oxide nanoparticles. J. Heat Tran. 1999; 121, 280-9.

[6] AS Hatwar and VM Kriplani. A review on heat transfer enhancement with nanofluid. Int. J. Adv. Res. Sci. Eng. 2014; 3, 175-83.

[7] KA Hamid, WH Azmi, R Mamat, NA Usri and G Najafi. Effect of temperature on heat transfer coefficient of titanium dioxide in ethylene glycol-based nanofluid. J. Mech. Eng. Sci. 2015; 8, 136775.

[8] WH Azmi, KV Sharma, R Mamat, ABS Alias and II Misnon. Correlations for thermal conductivity and viscosity of water based nanofluids. IOP Conf. Ser. Mater. Sci. Eng. 2012; 36, 012029.

[9] KA Hamid, WH Azmi, R Mamat and NA Usri. Thermal conductivity enhancement of aluminium oxide nanofluid in ethylene glycol. Appl. Mech. Mater. 2014; 660, 730-4.

[10] WH Azmi, NA Usri, R Mamat, KV Sharma and MM Noor. Force convection heat transfer of $\mathrm{Al}_{2} \mathrm{O}_{3}$ nanofluids for different based ratio of water: Ethylene glycol mixture. Appl. Therm. Eng. 2017; 112, 707-719.

[11] WH Azmi, KA Hamid, NA Usri, R Mamat and KV Sharma. Heat transfer augmentation of ethylene glycol: Water nanofluids and applications - A review. Int. Comm. Heat Mass Tran. 2016; 75, 13-23.

[12] MH Esfe, AAA Arani, M Rezaie, WM Yan and A Karimipour. Experimental determination of thermal conductivity and dynamic viscosity of $\mathrm{Ag}-\mathrm{MgO} /$ water hybrid nanofluid. Int. Comm. Heat Mass Tran. 2015; 66. 189-95.

[13] A Moghadassi, E Ghomi and F Parvizian. A numerical study of water based $\mathrm{Al}_{2} \mathrm{O}_{3}$ and $\mathrm{Al}_{2} \mathrm{O}_{3}-\mathrm{Cu}$ hybrid nanofluid effect on forced convective heat transfer. Int. J. Therm. Sci. 2015; 92, 50-7.

[14] J Sarkar, P Ghosh and A Adil. A review on hybrid nanofluids: Recent research, development and applications. Renew. Sustain. Energ. Rev. 2015; 43, 164-77.

[15] R Sureshkumar, ST Mohideen and N Nethaji. Heat transfer characteristics of nanofluids in heat pipes: A review. Renew. Sustain. Energ. Rev. 2013; 20. 397-410.

[16] MH Hamzah, NAC Sidik, TL Ken, R Mamat and G Najafi. Factors affecting the performance of hybrid nanofluids: A comprehensive review. Int. J. Heat Mass Tran. 2017; 115, 630-46.

[17] NAC Sidik, MM Jamil, WMAA Japar and IM Adamu. A review on preparation methods, stability and applications of hybrid nanofluids. Renew. Sustain. Energ. Rev. 2017; 80, 1112-22.

[18] V Trisaksri and S Wongwises. Critical review of heat transfer characteristics of nanofluids. Renew. Sustain. Energ. Rev. 2007; 11, 512-23.

[19] LS Sundar, MK Singh and ACM Sousa. Thermal conductivity of ethylene glycol and water mixture based $\mathrm{Fe}_{3} \mathrm{O}_{4}$ nanofluid. Int. Comm. Heat Mass Tran. 2013; 49, 17-24.

[20] G Paul, J Philip, B Raj, PK Das and I Manna. Synthesis, characterization, and thermal property measurement of nano- $\mathrm{Al}_{95} \mathrm{Zn}_{05}$ dispersed nanofluid prepared by a two-step process. Int. J. Heat Mass Tran. 2011; 54, 3783-8.

[21] FS Javadi, S Sadeghipour, R Saidur, G BoroumandJazi, B Rahmati, MM Elias and MR Sohel. The effects of nanofluid on thermophysical properties and heat transfer characteristics of a plate heat exchanger. Int. Comm. Heat Mass Tran. 2013; 44, 58-63. 
http://wjst.wu.ac.th

[22] DH Yoo, KS Hong and HS Yang. Study of thermal conductivity of nanofluids for the application of heat transfer fluids. Thermochim. Acta 2007; 455, 66-9.

[23] A Turgut, I Tavman, M Chirtoc, HP Schuchmann, C Sauter and S Tavman. Thermal conductivity and viscosity measurements of water-based $\mathrm{TiO}_{2}$ nanofluids. Int. J. Thermophys. 2009; 30, 1213-26.

[24] S Suresh, KP Venkitaraj, P Selvakumar and M Chandrasekar. Synthesis of $\mathrm{Al}_{2} \mathrm{O}_{3}-\mathrm{Cu} /$ water hybrid nanofluids using two step method and its thermo physical properties. Colloid. Surface Physicochem. Eng. Aspect. 2011; 388, 41-8.

[25] KA Hamid, WH Azmi, MF Nabil and R Mamat Experimental investigation of nanoparticle mixture ratios on $\mathrm{TiO}_{2}-\mathrm{SiO}_{2}$ nanofluids heat transfer performance under turbulent flow. Int. J. Heat and Mass Tran. 2018; 118, 617-27.

[26] CJ Ho, JB Huang, PS Tsai and YM Yang. Preparation and properties of hybrid water-based suspension of $\mathrm{Al}_{2} \mathrm{O}_{3}$ nanoparticles and MEPCM particles as functional forced convection fluid. Int. Comm. Heat Mass Tran. 2010; 37, 490-4.

[27] O Soltani and M Akbari. Effects of temperature and particles concentration on the dynamic viscosity of MgO-MWCNT/ethylene glycol hybrid nanofluid: Experimental study. Phys. E Low Dimens. Syst. Nanostruct. 2016; 84, 564-70.

[28] LS Sundar, KV Sharma, MK Singh and ACM Sousa. Hybrid nanofluids preparation, thermal properties, heat transfer and friction factor: A review. Renew. Sustain. Energ. Rev. 2017; 68, 18598.

[29] H Setia, R Gupta and RK Wanchoo. Stability of nanofluids. Mater. Sci. Forum. 2013; 757, 139-49.

[30] WH Azmi, KA Hamid, R Mamat, KV Sharma and MS Mohamad. Effects of working temperature on thermo-physical properties and forced convection heat transfer of $\mathrm{TiO}_{2}$ nanofluids in water: Ethylene glycol mixture. Appl. Therm. Eng. 2016; 106, 1190-9.

[31] WH Azmi, KA Hamid, NA Usri, R Mamat and MS Mohamad. Heat transfer and friction factor of water and ethylene glycol mixture based $\mathrm{TiO}_{2}$ and $\mathrm{Al}_{2} \mathrm{O}_{3}$ nanofluids under turbulent flow. Int. Comm. Heat Mass Tran. 2016; 76, 24-32.

[32] KA Hamid, WH Azmi, MF Nabil, R Mamat and KV Sharma. Experimental investigation of thermal conductivity and dynamic viscosity on nanoparticle mixture ratios of $\mathrm{TiO}_{2}-\mathrm{SiO}_{2}$ nanofluids. Int. J. Heat Mass Tran. 2018; 116, 1143-52.

[33] ASHRAE. Fundamentals. American Society of Heating, Refrigerating and Air-Conditioning Engineers, Atlanta, 2009.

[34] MCS Reddy and VV Rao. Experimental studies on thermal conductivity of blends of ethylene glycol-water-based $\mathrm{TiO}_{2}$ nanofluids. Int. Comm. Heat Mass Tran. 2013; 46, 31-6.

[35] M Bahrami, M Akbari, A Karimipour and M Afrand. An experimental study on rheological behavior of hybrid nanofluids made of iron and copper oxide in a binary mixture of water and ethylene glycol: Non-Newtonian behavior. Exp. Therm. Fluid Sci. 2016; 79, 231-7.

[36] AAM Redhwan, WH Azmi, MZ Sharif and R Mamat. Development of nanorefrigerants for various types of refrigerant based: A comprehensive review on performance. Int. Comm. Heat Mass Tran. 2016; 76, 285-93.

[37] MM Ghosh, S Ghosh and SK Pabi. Effects of particle shape and fluid temperature on heat-transfer characteristics of nanofluids. J. Mater. Eng. Perform. 2013; 22, 1525-9.

[38] M Asadi and A Asadi. Dynamic viscosity of MWCNT/ZnO-Engine oil hybrid nanofluid: An experimental investigation and new correlation in different temperatures and solid concentrations. Int. Comm. Heat Mass Tran. 2016; 76, 41-5.

[39] MF Nabil, WH Azmi, KA Hamid, R Mamat and FY Hagos. An experimental study on the thermal conductivity and dynamic viscosity of $\mathrm{TiO}_{2}-\mathrm{SiO}_{2}$ nanofluids in water: Ethylene glycol mixture. Int. Comm. Heat Mass Tran. 2017; 86, 181-9.

[40] SMS Murshed, KC Leong and C Yang. Investigations of thermal conductivity and viscosity of nanofluids. Int. J. Therm. Sci. 2008; 47, 560-8.

[41] WH Azmi, KV Sharma, PK Sarma, R Mamat and G Najafi. Heat transfer and friction factor of water based $\mathrm{TiO}_{2}$ and $\mathrm{SiO}_{2}$ nanofluids under turbulent flow in a tube. Int. Comm. Heat Mass Tran. 2014; 59, 30-8. 
[42] J Garg, B Poudel, M Chiesa, JB Gordon, JJ Ma, JB Wang, ZF Ren, YT Kang, H Ohtani and $\mathrm{J}$ Nanda. Enhanced thermal conductivity and viscosity of copper nanoparticles in ethylene glycol nanofluid. J. Appl. Phys. 2008; 103, 074301.

[43] AI Ramadhan, WH Azmi, R Mamat, KA Hamid and S Norsakinah. Investigation on stability of trihybrid nanofluids in water-ethylene glycol mixture. IOP Conf. Ser. Mater. Sci. Eng. 2019; 469, 012068.

[44] AI Ramadhan, WH Azmi and R Mamat. Heat transfer characteristics of car radiator using tri-hybrid nanocoolant. IOP Conf. Ser. Mater. Sci. Eng. 2020; 863, 012054.

[45] AI Ramadhan, WH Azmi, R Mamat, KA Hamid. Experimental and numerical study of heat transfer and friction factor of plain tube with hybrid nanofluids. Case Studies in Thermal Engineering, 2020, 22: 100782.

[46] AI Ramadhan, E Diniardi, E Dermawan. Numerical study of effect parameter fluid flow nanofluid $\mathrm{Al}_{2} \mathrm{O}_{3}$-water on heat transfer in corrugated tube. AIP Conference Proceedings. AIP Publishing LLC, 2016. p. 050003.

[47] MA Fikri, FF Asri, WM Faizal, HK Adli, R Mamat, WH Azmi, AI Ramadhan, T Yusaf. Effects of heat transfer based water for three square multilayer absorber solar collector. IOP Conference Series: Materials Science and Engineering. IOP Publishing, 2020. p. 012078.

[48] WH Azmi, K Abdul Hamid, AI Ramadhan, AIM Shaiful. Thermal hydraulic performance for hybrid composition ratio of $\mathrm{TiO}_{2}-\mathrm{SiO}_{2}$ nanofluids in a tube with wire coil inserts. Case Studies in Thermal Engineering, 2021, 25: 100899.

[49] MA Fikri, WM Faizal, HK Adli, Z Bo, XX Jiang and AI Ramadhan. Investigation on stability of $\mathrm{TiO}_{2}-\mathrm{SiO}_{2}$ nanofluids with ratio (70: 30) in W/EG mixture (60: 40). In: IOP Conference Series: Materials Science and Engineering. IOP Publishing, 2021. p. 012020. 